\title{
Pharmacology and Distribution of Norepinephrine Transporters in the Human Locus Coeruleus and Raphe Nuclei
}

\author{
Gregory A. Ordway, ${ }^{1}$ Craig A. Stockmeier, ${ }^{2}$ Garrick W. Cason, ${ }^{1}$ and Violetta Klimek ${ }^{1}$ \\ ${ }^{1}$ Department of Psychiatry and Human Behavior and Department of Pharmacology, University of Mississippi Medical \\ Center, Jackson, Mississippi 39216, and 2Department of Psychiatry, Case Western Reserve University, Cleveland, \\ Ohio 44106
}

The norepinephrine transporter (NET) is a site of action for tricyclic antidepressant drugs and for drugs of abuse such as amphetamine and cocaine. In this study, the binding of $\left[{ }^{3} \mathrm{H}\right]$ nisoxetine to NETs in the noradrenergic cell group, the locus coeruleus, and the serotonergic cell groups, the dorsal raphe nuclei, was measured autoradiographically in postmortem human brain. $\left[{ }^{3} \mathrm{H}\right]$ nisoxetine binding was unevenly distributed along the rostral-caudal axis of the locus coeruleus and correlated positively with numbers of neuromelanin-containing (noradrenergic) cells along the axis of the locus coeruleus within individuals. Binding densities of $\left[{ }^{3} \mathrm{H}\right]$ nisoxetine in dorsal raphe nuclei were similar to that in the locus coeruleus. $\left[{ }^{3} \mathrm{H}\right]$ nisoxetine binding was unevenly distributed along the entire rostral-caudal extent of the dorsal raphe, with the highest binding occurring in the interfascicular and ventral nuclei. A moderate amount of $\left[{ }^{3} \mathrm{H}\right]$ nisoxetine binding was also observed in the median raphe nucleus. The specificity of $\left[{ }^{3} \mathrm{H}\right]$ nisoxetine binding to NETs in monoaminergic nuclei was assessed by measuring the inhibition of its binding by desipramine, imipramine, or citalopram. The order of affinities of these drugs was identical in the locus coeruleus and dorsal and median raphe and was characteristic of binding to NETs (desipramine $>$ imipramine $>$ citalopram). Thus, high levels of NETs and an uneven distribution of NETs occur in the locus coeruleus as well as in the dorsal raphe nuclei of the human.

Key words: norepinephrine transporters; norepinephrine uptake; antidepressants; locus coeruleus; dorsal raphe nucleus; cocaine
The discovery of the therapeutic effectiveness of imipramine in depression nearly 40 years ago by the Swiss physician Roland Kuhn heralded a new age in the treatment of this psychiatric disorder. Since then, many drugs have been developed that selectively inhibit the transport of norepinephrine and/or serotonin. Over the years since the discovery of imipramine, considerable emphasis of drug development has been placed on the relative pharmacological selectivity of these compounds for either the norepinephrine or the serotonin transporters.

Recently, the cloning and sequencing of the norepinephrine transporters (NETs) have yielded insight into the structure, function, and distribution of these targets of antidepressant drug action. Like other monoamine transporters, the NET is a membrane glycoprotein with 12 membrane-spanning domains and is electrogenic (Pacholczyk et al., 1991; Blakely et al., 1994; Barker and Blakely, 1995). To date, subtypes of the NET have not been described. In rats, mRNA for the NET is localized in cell bodies of noradrenergic neurons in the brainstem, including the locus coeruleus (Pacholczyk et al., 1991). Autoradiography of the binding of the highly selective NET radioligand $\left[{ }^{3} \mathrm{H}\right]$ nisoxetine has revealed NET binding in the immediate region of the locus coeruleus, concentrations of which are the highest in the rat brain

Received Sept. 4, 1996; revised Dec. 9, 1996; accepted Dec. 19, 1996.

This research was supported by National Institutes of Health Grants MH 46692 and MH45488 and the American Suicide Foundation. We gratefully acknowledge the technical assistance of Ginny Dilley and Laura Shapiro (Case Western Reserve University), the Staff of the Cuyahoga County Coroner's Office (Cleveland, OH), and Stephen Luker (University of Mississippi Medical Center). We also acknowledge Dr. Ian A. Paul for advice concerning the statistical analyses of data.

Correspondence should be addressed to Dr. Gregory A. Ordway, Department of Psychiatry and Human Behavior, University of Mississippi Medical Center, 2500 North State Street, Jackson, MS 39216-4505.

Copyright (C) 1997 Society for Neuroscience $0270-6474 / 97 / 171710-10 \$ 05.00 / 0$
(Tejani-Butt et al., 1990; Tejani-Butt, 1992). Interestingly, moderate concentrations of $\left[{ }^{3} \mathrm{H}\right]$ nisoxetine binding in a serotonergic cell body region, the dorsal raphe nucleus, have also been reported in rats (Tejani-Butt, 1992) and humans (Donnan et al., 1991). NET transporters in the dorsal raphe presumably reside on terminals of noradrenergic fibers that are known to innervate the dorsal raphe (Saavedra et al., 1976; Fuxe et al., 1978; Levitt and Moore, 1979; Baraban and Aghajanian, 1981) and illustrate the interconnection of the central noradrenergic and serotonergic neuronal systems.

The locus coeruleus (Foote et al., 1983) and dorsal raphe (Tork and Hornung, 1990) nuclei are complex cell groups that are organized topographically with respect to their projection areas. Previous investigators have demonstrated distinct cytoarchitectonic patterns and uneven cell densities within each of the nuclei (Olszewski and Baxter, 1954; Baker et al., 1990, 1991; Tork and Hornung, 1990). The well defined morphological characteristics of these cell groups suggest that the distribution of NETs within the locus coeruleus and dorsal raphe may also be distinctive. The growing interest in the putative role of NETs in psychiatric disease underscores the importance of a detailed description of the distribution of these proteins in relation to cellular morphometry. In this study, we used $\left[{ }^{3} \mathrm{H}\right]$ nisoxetine to determine the distribution of NETs within the human locus coeruleus and dorsal raphe. $\left[{ }^{3} \mathrm{H}\right]$ nisoxetine has a high affinity for NETs (Tejani-Butt et al., 1990; TejaniButt, 1992; Tejani-Butt and Ordway, 1992) and does not possess the complications of other ligands used for analysis of NETs, i.e., binding to intracellular nonadrenergic sites (Laduron et al., 1982; Backstrom et al., 1989; Backstrom and Marcusson, 1990). 


\begin{tabular}{|c|c|c|c|c|c|}
\hline Subject & Age (years) & Gender & $\mathrm{PMD}^{a}(\mathrm{hr})$ & Toxicology & Cause of death \\
\hline $\mathrm{C}$ & 51 & Male & 20 & $\mathrm{NDD}^{b}$ & Heart disease \\
\hline $\mathrm{F}$ & 70 & Male & 4 & NDD & Pulmonary embolism \\
\hline G & 71 & Male & 23 & Chlorpheniramine & Heart disease, scleritis \\
\hline K & 26 & Male & 13 & NDD & Gun shot \\
\hline $\mathrm{O}$ & 78 & Female & 11 & NDD & Heart disease, diabetes, and hypertension \\
\hline $\mathrm{R}$ & 73 & Male & 22 & NDD & Myocardial infarction \\
\hline S & 67 & Female & 28 & NDD & Heart disease \\
\hline $\mathrm{Z}$ & 67 & Male & 19 & NDD & Myocardial infarction \\
\hline $\mathrm{Y}$ & 48 & Male & 21 & NDD & Heart disease, cardiomegaly \\
\hline $\mathrm{X}$ & 51 & Male & 11 & NDD & Myocardial infarction, cardiomegaly \\
\hline
\end{tabular}

${ }^{a}$ Postmortem duration.

${ }^{b}$ No drugs detected.

\section{MATERIALS AND METHODS}

Tissue material. Human brains were obtained from subjects at the time of autopsy at the Medical Examiner's Office of Cuyahoga County, Ohio, in accordance with an approved Institutional Review Board protocol. Demographic information derived from the coroner's records revealed that the brains came from individuals with no reported history of psychiatric or neurological diseases. A summary of subject information is outlined in Table 1.

At the time of autopsy, brainstems were isolated by making a transverse cut along a line from the rostral border of the superior colliculus to the exit point of the oculomotor nerve, and a second transverse cut at the caudal end of the locus coeruleus. Tissue lateral to the superior cerebellar peduncles was trimmed away. The block of brainstem tissue was then cut in a transverse plane at the level of frenulum, yielding two separate blocks of tissue. This final transverse cut was necessary to facilitate ease and accuracy of cutting of the tissue blocks with the cryostat microtome. Particular care was taken in the freezing process to maintain gross morphology. For example, the block of pontine tissue was dissected to form a flat surface on the ventral surface of the tissue blocks. This surface was placed on a hard piece of cardboard that was then lowered into the 2-methylbutane cooled on dry ice to $-50^{\circ} \mathrm{C}$ for quick freezing. Tissue blocks were then placed on powdered dry ice for $10 \mathrm{~min}$ and then stored in an ultracold freezer $\left(-83^{\circ} \mathrm{C}\right)$.

Tissue blocks were sectioned in a single transverse plane perpendicular to the floor of the fourth ventricle. The rostral surface of the block of tissue containing the dorsal raphe was mounted onto a specimen chuck, and the raphe was sectioned through its entire length sequentially beginning at its caudal end (at the frenulum). The caudal surface of the tissue block containing the locus coeruleus was mounted onto a specimen chuck and sectioned through its entire length beginning at its rostral end (at the frenulum). Tissue sections were cut (Leica, Cryocut 1800, Reichert-Jung) at $-16^{\circ} \mathrm{C}$ and thaw-mounted onto gelatin-coated microscope slides. Locus coeruleus and dorsal raphe sections were collected for morphometric and neurochemical measurements at $1 \mathrm{~mm}$ intervals. For the "locus coeruleus block," two 40- $\mu$ m-thick sections (for morphometry, cresyl violet staining), followed by four $20-\mu \mathrm{m}$-thick sections (for autoradiography of $\left[{ }^{3} \mathrm{H}\right]$ nisoxetine binding) were cut at each $1 \mathrm{~mm}$ interval. The "dorsal raphe block" was sectioned ( $20 \mu \mathrm{m}$ thickness) transversely at $\sim 1$ $\mathrm{mm}$ intervals, making sets of sections at four distinct levels. These sections were then processed (individually) with the following procedures: (1) autoradiography of NETs, using $\left[{ }^{3} \mathrm{H}\right]$ nisoxetine; (2) Nissl staining with cresyl violet to identify neuronal elements; (3) tyrosine hydroxylase immunohistochemistry to identify catecholaminergic neurons; and (4) tryptophan hydroxylase immunohistochemistry to identify serotonergic neurons. Outlines of morphological reference landmarks at matching levels for all of the subjects were carefully selected based on the neuronal morphology and density, according to the cytoarchitectonic maps of the region (Olszewski and Baxter, 1954; Baker et al., 1990).

Immunohistochemical studies. Sections of midbrain were warmed to room temperature, dried under a stream of cool air, and encircled with a PAP pen (Research Products International, Mount Prospect, IL). The sections were fixed $\left(4 \mathrm{hr}, 4^{\circ} \mathrm{C}\right)$ by immersion in PBS $(10 \mathrm{~mm}$ sodium phosphate, $150 \mathrm{~mm} \mathrm{NaCl}, \mathrm{pH} 7.4$ ) containing $4 \%$ paraformaldehyde. Sections were immersed three times for $20 \mathrm{~min}$ each at $4^{\circ} \mathrm{C}$ in $\mathrm{PBS}$ and then immersed for $10 \mathrm{~min}$ at $4^{\circ} \mathrm{C}$ in PBS containing $0.2 \%$ Triton $\mathrm{X}-100$ (Bio-Rad, Hercules, CA) and hydrogen peroxide $(0.5 \%$ actual final concentration). The sections were rinsed three times with PBS containing $0.2 \%$ Triton X-100 and preincubated for $1 \mathrm{hr}$ at room temperature in PBS containing $0.2 \%$ Triton X-100 and $1 \%$ normal horse serum. The sections were incubated by immersion in buffer containing PH8 and mouse antiphenylalanine hydroxylase (Cotton et al., 1988) for $40 \mathrm{hr}$ at $4^{\circ} \mathrm{C}$ followed by $1 \mathrm{hr}$ at room temperature. Other adjacent serial sections were incubated with mouse anti-tyrosine hydroxylase (Incstar, Stillwater, MN). PH8 was kindly supplied by Drs. Richard Cotton and Ian Jennings. PH8 and anti-tyrosine hydroxylase were diluted $1: 20,000$ and 1:16,000, respectively, in PBS containing $0.2 \%$ Triton X-100. Sections were then incubated for $1 \mathrm{hr}$ with biotinylated horse anti-mouse IgG secondary antibody (Vectastain Elite ABC kit, Vector Laboratories, Burlingame, CA) diluted 1:200 in PBS containing $0.2 \%$ Triton X-100 and $1 \%$ normal horse serum. Sections were rinsed three times by immersion in PBS containing $0.2 \%$ Triton X-100 and incubated for $1 \mathrm{hr}$ in avidin-biotin-horseradish peroxidase (HRP) conjugate. The secondary antibody and avidin-biotinHRP conjugate solutions were added drop-wise to horizontally placed slides. Slides were immersed three times for $5 \mathrm{~min}$ each in PBS containing $0.2 \%$ Triton $\mathrm{X}-100$ and immersed in $50 \mathrm{~mm}$ Tris-HCl, $\mathrm{pH} 7.6$, for 2-3 min. Slides were incubated in $50 \mathrm{~mm}$ Tris- $\mathrm{HCl}$ containing $0.05 \% 3,3^{\prime}$-diaminobenzidine tetrahydrochloride (Sigma, St. Louis, MO) and hydrogen peroxide $(0.01 \%$ actual final concentration) for $5 \mathrm{~min}$ or until adequate staining was observed. Slides were immersed in $50 \mathrm{~mm}$ Tris- $\mathrm{HCl}$ for 3 min, dried, lightly counter-stained with cresyl violet, dehydrated, and coverslipped.

Morphometry of the locus coeruleus. Two adjacent sections for morphometry were dried at room temperature and then stained with cresyl violet. Profiles, as defined by Coggeshall and Lekan (1996), of neuromelanin-pigmented neurons of the locus coeruleus were counted using a Nikon Optiphot microscope (magnification, 200×) and are referred to as neuromelanin-containing cells throughout this manuscript. Neuromelanin-containing cell counts were estimated by averaging independent counts made by two experimenters who were blind to subject information. For the two experimenters, the number of neuromelanincontaining cells at any particular level of a given subject never differed by $>5 \%$. A bilateral neuromelanin-containing cell count at each level was determined from the average of two adjacent sections for each level.

Quantitative autoradiography of $\left[{ }^{3} H\right]$ nisoxetine binding to NETs. The binding of $\left[{ }^{3} \mathrm{H}\right]$ nisoxetine to NETs was measured by quantitative autoradiography using the method of Tejani-Butt (1992). Briefly, transverse sections cut through the locus coeruleus and dorsal raphe nuclei at levels indicated were thaw-mounted onto gelatin-coated microscope slides. Sections were incubated with $3.0 \mathrm{~nm}\left[{ }^{3} \mathrm{H}\right]$ nisoxetine $(82 \mathrm{Ci} / \mathrm{mmol}$, American Radiolabeled Chemicals, St. Louis, MO) in buffer (50 mM Tris, 300 $\mathrm{mm} \mathrm{NaCl}, 5 \mathrm{~mm} \mathrm{KCl}, \mathrm{pH} 7.4$ ) at $4^{\circ} \mathrm{C}$ for $4 \mathrm{hr}$. Nonspecific binding was defined by $1 \mu \mathrm{M}$ mazindol. Nonspecific binding was $15 \%$ of total binding in the locus coeruleus and in the dorsal raphe. For competition experiments, sections were incubated with $3.0 \mathrm{nM}\left[{ }^{3} \mathrm{H}\right]$ nisoxetine in the presence of varying concentrations of competitors (desipramine, citalopram, and imipramine) at concentrations indicated.

After incubations, sections were washed in the same buffer three times at $4{ }^{\circ} \mathrm{C}$ for $5 \mathrm{~min}$ and then rinsed briefly $(2 \mathrm{sec})$ in ice-cold water before 
drying. Sections and brain mash-calibrated $\left[{ }^{3} \mathrm{H}\right]$ standards (American Radiolabeled Chemicals) were apposed to $\left[{ }^{3} \mathrm{H}\right]$-Ultrofilm (Leica Instruments, $\mathrm{GmbH}$ ) and exposed in X-ray cassettes at room temperature for $20 \mathrm{hr}$ for 4-6 weeks. Films were processed with GBX developer and fixer (Eastman Kodak, Rochester, NY) at $17^{\circ} \mathrm{C}$. After autoradiography, the same sections were stained lightly with the cresyl violet for the anatomical identification. Densitometric measurements of autoradiograms were made using an image analysis system (MCID M2, Imaging Research, St. Catherines, Ontario). Autoradiograms of locus coeruleus were analyzed by simultaneously overlaying the image of the autoradiogram with the image of the same, histologically stained section. For the locus coeruleus, the smallest region encompassing all cell bodies containing neuromelanin pigment was outlined. For the dorsal raphe, $\left[{ }^{3} \mathrm{H}\right]$ nisoxetine binding was measured in its subnuclei. Raphe subnuclei were distinguished as described by Baker et al. (1990, 1991), and their borders were drawn on digital templates constructed from digitized images of tryptophan hydroxylase immunohistochemistry on the nearest slide-mounted sections (Stockmeier et al., 1996). The digital templates of immunohistochemistry were superimposed onto autoradiographic images. Specific binding was defined as the difference between total and nonspecific binding. The binding of radioligands to the left and right side of locus coeruleus cell groups as well as for the left and right sides of bilateral subnuclei of the raphe were averaged because there was no significant difference in $\left[{ }^{3} \mathrm{H}\right]$ nisoxetine binding between sides (data not shown).

Statistics. The distribution of locus coeruleus cells and $\left[{ }^{3} \mathrm{H}\right]$ nisoxetine binding was assessed by ANOVA for repeated measures using Systat (Systat, Inc., Evanston, IL). Linear regression analysis was used to compute correlations between cell numbers and binding and between age or postmortem interval and binding or cell number (GraphPad Prism, GraphPad Software, San Diego, CA). IC $_{50}$ values were computed by nonlinear regression analysis (GraphPad Prism) of data from competition experiments. Competition data were fit to a model assuming a one-site interaction.

\section{RESULTS}

The binding of $\left[{ }^{3} \mathrm{H}\right]$ nisoxetine to NETs and morphometric examinations were performed on the locus coeruleus from 7 subjects (subjects C, F, G, K, O, R, S; Table 1). The age of these subjects ranged from 26 to 78 years $(62.3 \pm 6.8)$, and the postmortem intervals ranged from 4 to $28 \mathrm{hr}(17.3 \pm 3.1)$. $\left[{ }^{3} \mathrm{H}\right]$ nisoxetine binding to NETs and morphometric examinations were performed on the dorsal raphe nuclei from 6 subjects (subjects C, F, G, Z, Y, X; Table 1). The age of subjects ranged from 48 to 71 years $(59.7 \pm 4.4)$, and the postmortem delays ranged from 4 to 23 hr $(16.3 \pm 3.0)$.

\section{Distribution of $\left[{ }^{3} \mathrm{H}\right]$ nisoxetine binding in the locus coeruleus}

The binding of $\left[{ }^{3} \mathrm{H}\right]$ nisoxetine was measured in transverse sections cut at $1 \mathrm{~mm}$ intervals along the rostral-caudal axis of the brainstem containing locus coeruleus. $\left[{ }^{3} \mathrm{H}\right]$ nisoxetine binding to NETs was unevenly distributed all along the axis of the locus coeruleus (Fig. 1). At the rostral portion of the locus coeruleus, the binding of $\left[{ }^{3} \mathrm{H}\right]$ nisoxetine was less localized to the cellular region of the locus coeruleus, and moderate amounts of binding were also observed in surrounding areas such as the central gray and the median and dorsal raphe nuclei (Fig. 1, levels 0 to +4$)$. The highest amount of $\left[{ }^{3} \mathrm{H}\right]$ nisoxetine binding was found in the middle portion of the locus coeruleus (Fig. 1, level +6 ). At middle levels of the locus coeruleus (levels +5 to +7 ), much less binding was observed in areas surrounding the locus coeruleus, except for a moderate amount of binding in the median raphe nucleus. At the caudal one-third of the locus coeruleus, the binding of $\left[{ }^{3} \mathrm{H}\right]$ nisoxetine was highly localized to the compact cellular region of the nucleus (Fig. 1, levels +8 and +10 ), with extremely low levels of binding in surrounding areas.

Quantitative evaluation of the specific binding of $\left[{ }^{3} \mathrm{H}\right]$ nisoxetine to NETs in the locus coeruleus revealed a significant rostral- caudal gradient along its entire length $\left(F_{(9,54)}=34.7 ; p<0.001\right)$. This uneven distribution of $\left[{ }^{3} \mathrm{H}\right]$ nisoxetine binding was paralleled by a significant uneven distribution of the number of neuromelanin-containing cells per level $\left(F_{(12,72)}=48.0 ; p<\right.$ $0.001)$. At a given level, both the number of neuromelanincontaining cells and the amount of $\left[{ }^{3} \mathrm{H}\right]$ nisoxetine binding increased steadily from the rostral pole of the nucleus to its medial part and then decreased steadily to the caudal end of the locus coeruleus (Fig. 2). Considering all subjects and all levels of the locus coeruleus together, the specific binding of $\left[{ }^{3} \mathrm{H}\right]$ nisoxetine to NETs was positively correlated with the number of neuromelanincontaining cells per level $\left(r^{2}=0.61 ; p<0.0001\right.$; Fig. 3$)$. The general topographic patterns of $\left[{ }^{3} \mathrm{H}\right]$ nisoxetine binding and neuromelanin-containing cells along the rostral-caudal axis of the locus coeruleus were nearly identical for each subject studied (Fig. 2). However, it is noteworthy that the amount of $\left[{ }^{3} \mathrm{H}\right]$ nisoxetine binding at any particular level of the locus coeruleus varied considerably among the subjects. A good example of this individual variability of binding to NET is the comparison of subjects $G$ and R. These two subjects have similar ages (71 and 73 years, respectively), similar postmortem intervals (23 and $22 \mathrm{hr}$ ), and similar numbers of neuromelanin-containing cells at the different levels of the locus coeruleus. However, the amount of $\left[{ }^{3} \mathrm{H}\right]$ nisoxetine binding at many levels of the locus coeruleus is strikingly different between these two individuals (subject $\mathrm{R}$ almost twice that of subject $\mathrm{G}$ ).

\section{Distribution and pharmacology of $\left[{ }^{3} \mathrm{H}\right]$ nisoxetine binding in the dorsal raphe}

The binding of $\left[{ }^{3} \mathrm{H}\right]$ nisoxetine at levels of the brainstem rostral to the frenulum was localized in the region of the dorsal raphe nuclei. Sections adjacent to those used for $\left[{ }^{3} \mathrm{H}\right]$ nisoxetine binding were immunostained using $\mathrm{PH} 8$, which labels tryptophan hydroxylase-positive neurons (Cotton et al., 1988). Subnuclei of the dorsal raphe were identified in immunostained sections as described by Baker et al. (1991) and Stockmeier et al. (1996). $\left[{ }^{3} \mathrm{H}\right]$ nisoxetine binding was unevenly distributed along the entire rostral-caudal axis of the dorsal raphe nucleus (Fig. 1, levels 0 to -6) and demonstrated distinct patterns of binding within the subnuclei of the dorsal raphe at each level. The highest amounts of $\left[{ }^{3} \mathrm{H}\right]$ nisoxetine binding within the dorsal raphe were found in the ventral subnucleus, ventrolateral subnucleus, and interfascicular subnucleus (Table 2). Near the frenulum (Fig. 1, levels 0 and $-2)$, the binding of $\left[{ }^{3} \mathrm{H}\right]$ nisoxetine in the caudal nucleus of the dorsal raphe was approximately twice that in the locus coeruleus at the same level.

We were surprised to find $\left[{ }^{3} \mathrm{H}\right]$ nisoxetine binding in the dorsal raphe nuclei that was as high or higher than $\left[{ }^{3} \mathrm{H}\right]$ nisoxetine binding in many levels of the locus coeruleus. We considered the possibility that the high amounts of binding of $\left[{ }^{3} \mathrm{H}\right]$ nisoxetine in the dorsal raphe nuclei and in the median raphe (see above) might represent binding to serotonin transporters. To check the specificity of the binding of $\left[{ }^{3} \mathrm{H}\right]$ nisoxetine to NETs, competition binding experiments were performed to determine the rank order of affinities of desipramine, imipramine, and citalopram at these $\left[{ }^{3} \mathrm{H}\right]$ nisoxetine-labeled sites. The $\mathrm{IC}_{50}$ values of drugs for the inhibition of $\left[{ }^{3} \mathrm{H}\right]$ nisoxetine binding were nearly identical in the human locus coeruleus and dorsal raphe subnuclei (Fig. 4). The rank order of affinities of these drugs is characteristic of binding to NETs (desipramine $>$ imipramine $>$ citalopram) in all three regions.

The binding of $\left[{ }^{3} \mathrm{H}\right]$ nisoxetine in the dorsal raphe nuclei was 


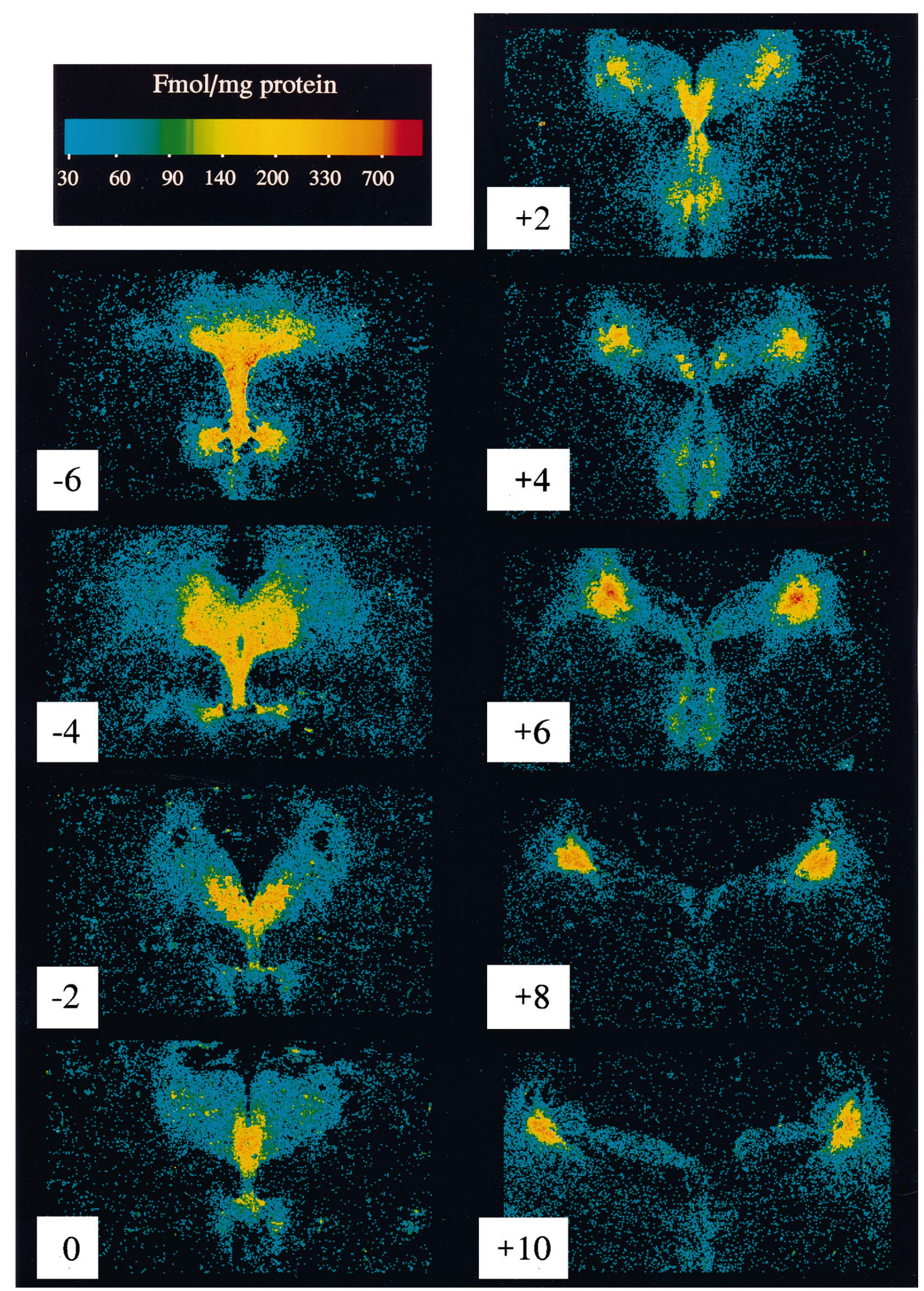

Figure 1. Digitized autoradiograms of the specific binding of $\left[{ }^{3} \mathrm{H}\right]$ nisoxetine to NETs at multiple levels along the rostral-caudal axis of the human dorsal raphe and locus coeruleus (subject F). Transverse sections are numbered in relation to the distance in mm from the frenulum (" 0 "), positive numbers in the caudal direction and negative numbers in the rostral direction. Each image of the specific binding of $\left[{ }^{3} \mathrm{H}\right]$ nisoxetine was generated by digitally subtracting the image of nonspecific binding from the image of total binding with the aid of a computer. 

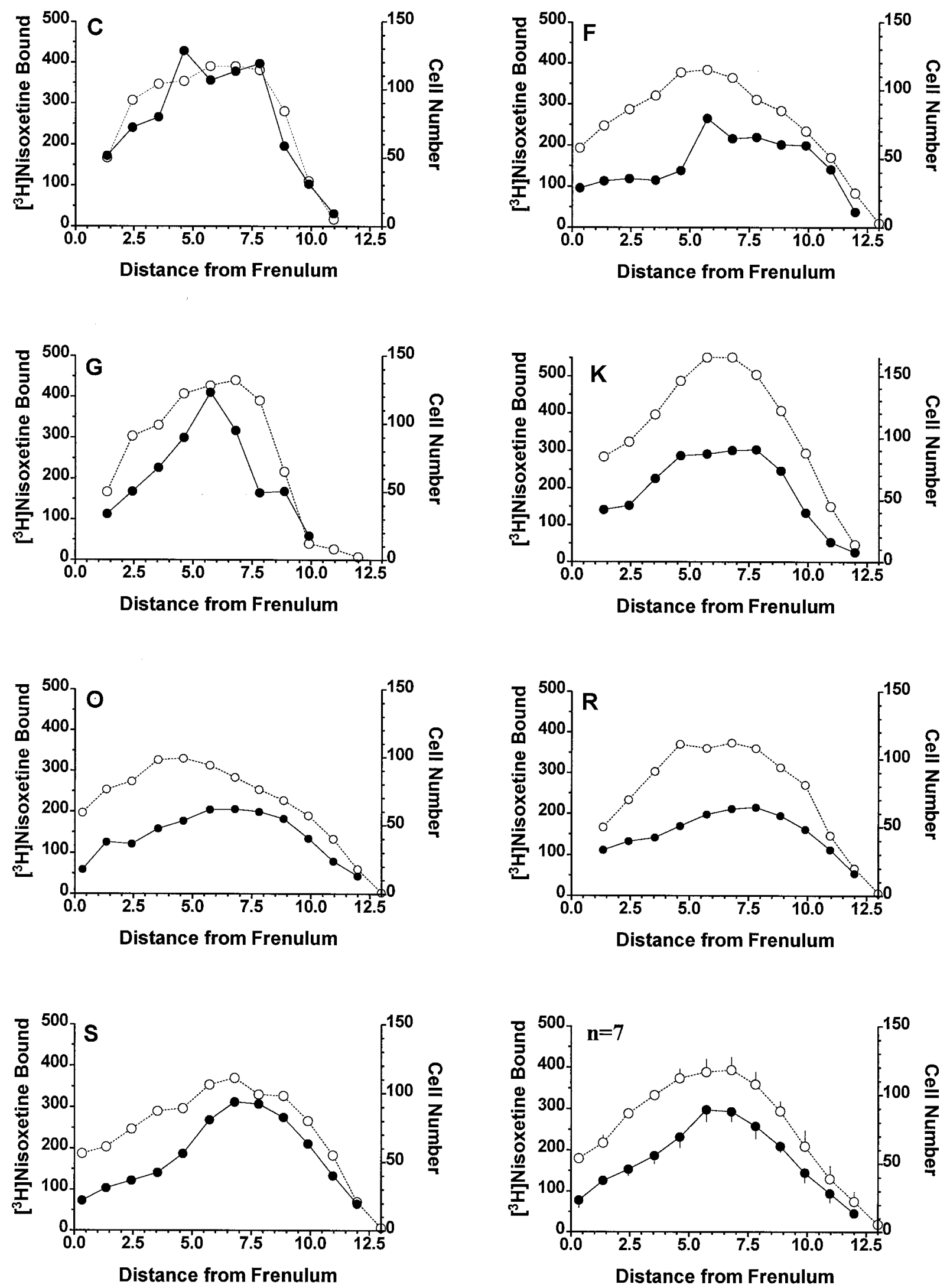

Figure 2. The distribution of specific binding of $\left[{ }^{3} \mathrm{H}\right]$ nisoxetine (fmol/mg protein) to NETs $(\bullet)$ and neuromelanin-containing cell number $(\bigcirc)$ along the rostral-caudal axis of the human locus coeruleus from 7 subjects. The letter in the top left corner of each graph identifies the subject (Table 1). Values are the average of four estimations (left and right sides in duplicates) for binding and for the cell counts. The abscissa is the distance from the frenulum along the rostral-caudal axis of the locus coeruleus. The graph in the lower right shows the mean \pm SEM of binding and cell number for all 7 subjects. 


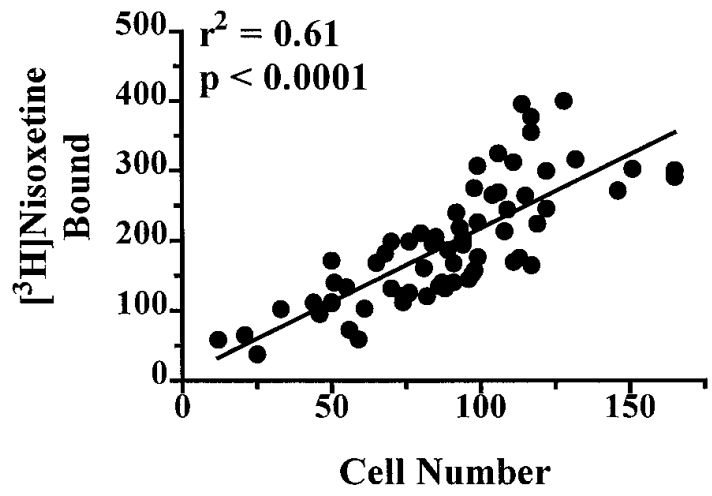

Figure 3. The relationship between neuromelanin-containing cell counts and the binding of $\left[{ }^{3} \mathrm{H}\right]$ nisoxetine to NETs at all levels of the locus coeruleus from 7 subjects. Values are the average of four estimations (left and right sides in duplicates) for binding and cell counts.

highest in the immediate cell body region of these nuclei. The relationship between $\left[{ }^{3} \mathrm{H}\right]$ nisoxetine binding and tryptophan hydroxylase-positive or tyrosine hydroxylase-positive neurons was examined by immunostaining for tyrosine hydroxylase and tryptophan hydroxylase (PH8) in sections adjacent to those used for binding (Fig. 5). The tyrosine hydroxylase-immunoreactive staining was present in a few neuronal soma $(<10)$ and in many fibers within the dorsal raphe subnuclei (Fig. $5 B$ ). Tyrosine hydroxylase and PH8 immunostaining was also observed in the substantia nigra. The binding of $\left[{ }^{3} \mathrm{H}\right]$ nisoxetine was localized within the area of dorsal raphe subnuclei and corresponded to the pattern of immunostaining with PH8 and tyrosine hydroxylase antibodies in this region. In contrast, little or no $\left[{ }^{3} \mathrm{H}\right]$ nisoxetine binding was observed in the region of substantia nigra (Fig. 5C).

\section{Age, postmortem interval, and laterality}

Although there were uneven distributions of ages and postmortem intervals among the study subjects, we attempted to determine whether there were significant correlations between these variables and $\left[{ }^{3} \mathrm{H}\right]$ nisoxetine binding (despite the small power in regression analysis using data from 6-7 subjects). There were no significant correlations between age and the binding of $\left[{ }^{3} \mathrm{H}\right]$ nisoxetine in the locus coeruleus or dorsal raphe nuclei at any level (data not shown). Furthermore, there were no significant correlations between postmortem intervals and the binding of $\left[{ }^{3} \mathrm{H}\right]$ nisoxetine in the locus coeruleus or dorsal raphe (data not shown). The amount of $\left[{ }^{3} \mathrm{H}\right]$ nisoxetine binding to NETs and the number of neuromelanin-containing cells per section, at any particular level on the two sides of the locus coeruleus, differed by an average of $5 \%$, but this difference did not reach statistical significance.

\section{DISCUSSION}

The present study is the first detailed examination of the distribution of NETs within the locus coeruleus and the dorsal raphe nuclei. A high density of radioligand binding to NETs was observed in both the locus coeruleus and the dorsal raphe nuclei. Furthermore, consistently uneven densities of $\left[{ }^{3} \mathrm{H}\right]$ nisoxetine binding to NETs along the rostral-caudal axis of the locus coeruleus and dorsal raphe nuclei were observed for all subjects studied. Within the dorsal raphe subnuclei, there were distinct patterns of binding of $\left[{ }^{3} \mathrm{H}\right]$ nisoxetine. In contrast to serotonergic and noradrenergic cell groups, virtually no $\left[{ }^{3} \mathrm{H}\right]$ nisoxetine binding to NETs was observed in a dopaminergic cell group (substantia
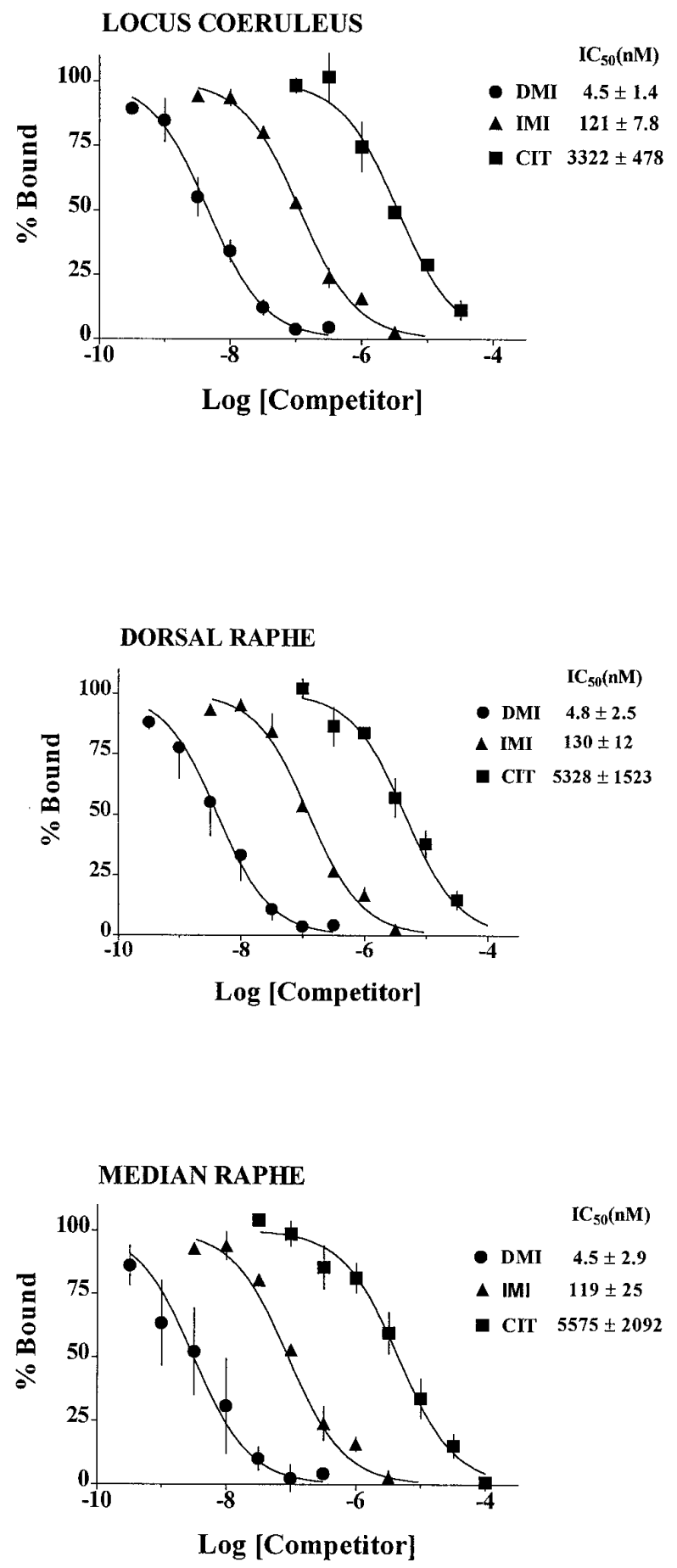

Figure 4. Inhibition of the binding of $\left[{ }^{3} \mathrm{H}\right]$ nisoxetine to NETs $(\bullet$, desipramine; $\boldsymbol{\Delta}$, imipramine; $\mathbf{\square}$, citalopram) in the human locus coeruleus, dorsal raphe, and median raphe ( $n=3$ subjects).

nigra). The detailed distribution of $\left[{ }^{3} \mathrm{H}\right]$ nisoxetine binding to NETs described here extends previous examinations of NET distribution in the human brain (Gross-Isseroff et al., 1988; Donnan et al., 1991) and provides a basis for future studies that evaluate levels of NETs in brainstem monoaminergic nuclei from individuals with psychiatric or neurological illnesses.

Previous investigations of the distribution of NETs in the human brain have used the radioligands $\left[{ }^{3} \mathrm{H}\right]$ desipramine or $\left[{ }^{3} \mathrm{H}\right]$ mazindol (Gross-Isseroff et al., 1988; Donnan et al., 1991). 


\begin{tabular}{|c|c|c|c|c|c|c|}
\hline \multicolumn{7}{|c|}{ Rostral to frenulum $(n=6)$} \\
\hline Level & $\mathrm{DRC}^{a}$ & DRD & DRIF & DRV & DRVL & 4 \\
\hline-6 & - & $135.5 \pm 41.2$ & $334.0 \pm 69.2$ & $273.2 \pm 51.0$ & - & - \\
\hline-4 & - & $153.3 \pm 42.0$ & $231.1 \pm 42.6$ & $299.8 \pm 80.3$ & $277.1 \pm 79.7$ & $30.5 \pm 6.1$ \\
\hline-2 & - & $97.7 \pm 15.6$ & $103.8 \pm 12.6$ & $176.0 \pm 28.0$ & $126.0 \pm 15.7$ & - \\
\hline 0 & $135.6 \pm 24.6$ & - & $153.1 \pm 32.6$ & - & - & - \\
\hline \multicolumn{7}{|c|}{ Caudal to frenulum $(n=7)$} \\
\hline Level & DRC & MR & $\mathrm{LC}$ & & & \\
\hline+2 & $176 \pm 19$ & $101 \pm 11$ & $78 \pm 18$ & & & \\
\hline+4 & $130 \pm 17$ & $75 \pm 11$ & $153 \pm 16$ & & & \\
\hline+6 & - & - & $231 \pm 26$ & & & \\
\hline+8 & - & - & $293 \pm 25$ & & & \\
\hline+10 & - & - & $199 \pm 00$ & & & \\
\hline
\end{tabular}

Levels indicate approximate distances from the frenulum (negative numbers in the direction rostral to frenulum, positive numbers in the direction caudal to frenulum).

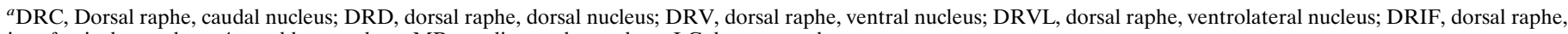
interfascicular nucleus; 4 , trochlear nucleus; MR, median raphe nucleus; LC, locus coeruleus.

Although $\left[{ }^{3} \mathrm{H}\right]$ desipramine binds with high affinity to NETs, it also binds to intracellular nonadrenergic sites (Laduron et al., 1982; Backstrom et al., 1989; Backstrom and Marcusson, 1990), making interpretation of binding results difficult. $\left[{ }^{3} \mathrm{H}\right]$ mazindol binds with high affinity to NETs but also binds to dopamine transporters so that nonspecific binding must be measured by careful choice of a displacing ligand and its concentration (Donnan et al., 1991). In contrast to these radioligands, $\left[{ }^{3} \mathrm{H}\right]$ nisoxetine does not possess such complications. $\left[{ }^{3} \mathrm{H}\right]$ nisoxetine has a high affinity for NETs $\left(K_{\mathrm{D}}=0.7 \mathrm{nM}\right)$ and a low affinity for serotonin transporters $\left(K_{\mathrm{D}}>\right.$ $1 \mathrm{~mm})$ and dopamine transporters $\left(K_{\mathrm{D}}>1 \mathrm{~mm}\right.$; S. Tejani-Butt, personal communication) (Tejani-Butt et al., 1990; Tejani-Butt, 1992). $\left[{ }^{3} \mathrm{H}\right]$ nisoxetine has been used previously to measure NETs in rat and human brain (Tejani-Butt, 1992; Tejani-Butt and Ordway, 1992; Tejani-Butt et al., 1993).

Numerous findings indicate that NETs occur solely on noradrenergic neurons in the CNS (Pacholczyk et al., 1991; Lorang et al., 1994). For example, NET mRNA is localized to noradrenergic cell bodies (Lorang et al., 1994). The regional distribution of $\left[{ }^{3} \mathrm{H}\right]$ nisoxetine binding sites in rat brain is in close agreement with the distribution of noradrenergic terminals (Tejani-Butt, 1992). Furthermore, $\left[{ }^{3} \mathrm{H}\right]$ nisoxetine binding to NETs in the rat is virtually eliminated by neurotoxin treatments, e.g., 6-hydroxydopamine (Ordway, 1995) or DSP-4 (Tejani-Butt et al., 1990), which destroy noradrenergic nerve terminals (Bloom et al., 1969; Bartholini et al., 1970; Fritschy and Grzanna, 1989). Thus, the distribution of the specific binding $\left[{ }^{3} \mathrm{H}\right]$ nisoxetine binding to NETs would be expected to parallel the distribution of noradrenergic projections in the brain.

In the locus coeruleus, there was a strong relationship between the amount of $\left[{ }^{3} \mathrm{H}\right]$ nisoxetine bound to NETs and the number of noradrenergic neurons at any particular level. Recently, we made a similar observation of the uneven distribution of $\mathrm{p}-\left[{ }^{125} \mathrm{I}\right]$ iodoclonidine binding to $\alpha_{2}$-adrenoceptors that follows the pattern of noradrenergic cell distribution in the human locus coeruleus (Klimek and Ordway, 1996). A strong correlation between amounts of $\left[{ }^{3} \mathrm{H}\right]$ nisoxetine binding to NET and numbers of neuromelanin-containing cells in the locus coeruleus would be consistent with the notion that these transporters occur on noradrenergic neurons of the locus coeruleus and their dendrites. There are, however, noradrenergic projections to the locus coer- uleus coming from more caudal noradrenergic cell groups, i.e., the lateral tegmental nuclei (Foote et al., 1983; Herbert and Saper, 1992; Van Bockstaele and Aston-Jones, 1992). Thus, it cannot be ruled out that at least some NETs labeled in the region of the locus coeruleus may also reside on terminal projections arising from these caudal noradrenergic cells.

In this study, noradrenergic neurons of the locus coeruleus were distinguished from other cells by visually identifying cells containing neuromelanin. Neuromelanin pigment appears as very dark granules and is characteristic of all catecholamine-containing neurons in humans (Bogerts, 1981). Neuromelanin may be a waste product resulting from oxidative catabolism of catecholamine and in locus coeruleus neurons appears to be colocalized with tyrosine hydroxylase, the rate-limiting enzyme for catecholamine synthesis (Mann and Yates, 1979; Baker et al., 1989; Chan-Palay and Asan, 1989). Iversen et al. (1983) have shown that counting locus coeruleus neurons that contain neuromelanin and those that contain dopamine- $\alpha$-hydroxylase gives the same number of cell counts in the human brain. Other studies have demonstrated similar results by counting tyrosine hydroxylase-immunoreactive neurons and the number of cells containing neuromelanin pigment in the same brains (Mann and Yates, 1979; Baker et al., 1989; Chan-Palay and Asan, 1989; Blanchard et al., 1993). Tyrosine hydroxylaseimmunoreactive cells that do not contain neuromelanin have been reported (Chan-Palay and Asan, 1989) in the human locus coeruleus, but these neurons occur in a small region of the locus coeruleus rostral to the frenulum, an area where cell counts and binding were not compared in the present study.

A high binding density of $\left[{ }^{3} \mathrm{H}\right]$ nisoxetine was also observed in subregions of the dorsal raphe and in the median raphe. In fact, at certain levels along the rostral-caudal axis of the brainstem, the binding of $\left[{ }^{3} \mathrm{H}\right]$ nisoxetine was considerably higher in the dorsal raphe than in the locus coeruleus at the same level, e.g., at the level of the frenulum. Despite the reported selectivity of $\left[{ }^{3} \mathrm{H}\right]$ nisoxetine for NETs in rat brain, we were initially concerned that $\left[{ }^{3} \mathrm{H}\right]$ nisoxetine was binding to human serotonin transporters, because these occur in high density in the immediate region of the raphe (Cortes et al., 1988; Hrdina et al., 1990; Gurevich and Joyce, 1996; Stockmeier et al., 1996). However, competition binding experiments revealed a rank order of affinities of transporter ligands that was characteristic of binding to NETs and uncharac- 

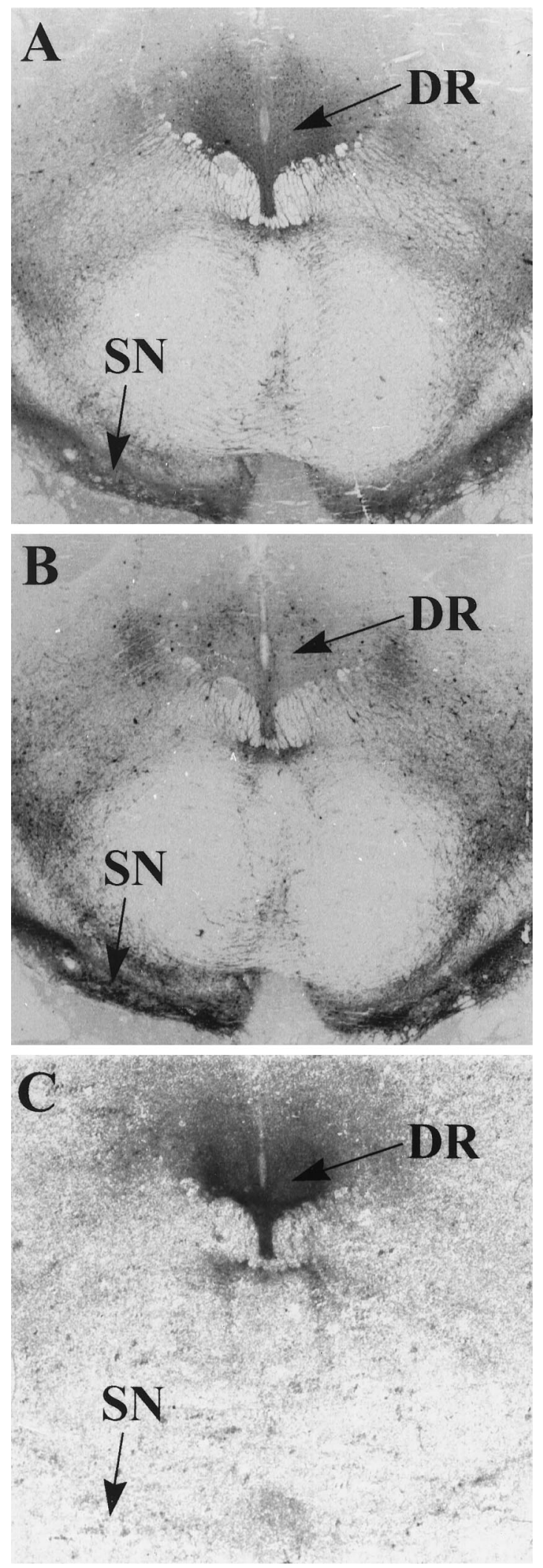

Figure 5. Digitized images of sections through the brainstem of $(A)$ tryptophan hydroxylase (PH8) immunoreactivity, $(B)$ tyrosine hydroxylase immunoreactivity, and $(C)$ the specific binding of $\left[{ }^{3} \mathrm{H}\right]$ nisoxetine. $D R$, Dorsal raphe; $S N$, substantia nigra. teristic for binding to serotonin or dopamine transporters (Hoffman et al., 1991; Pacholczyk et al., 1991; Hoffman, 1994; Cheetham et al., 1996). For example, the relative affinities of transporter ligands in the locus coeruleus, dorsal raphe, and median raphe were identical, i.e., desipramine $>$ imipramine $>$ citalopram. Furthermore, the $\mathrm{IC}_{50}$ values of these compounds were very similar in each of these regions. These data strongly support the conclusion that the dense binding of $\left[{ }^{3} \mathrm{H}\right]$ nisoxetine in noradrenergic (locus coeruleus) and serotonergic (raphe) nuclei of the human brainstem is to NETs.

There are several pieces of evidence suggesting that NETs in dorsal raphe nuclei reside on noradrenergic fibers projecting to these nuclei. First, there are catecholaminergic neurons (presumably noradrenergic) in the dorsal raphe nuclei, but their number is low relative to the number of serotonergic neurons. According to Baker et al. (1991), catecholaminergic cells are found only in the rostral part of the dorsal raphe and their number is $\sim 5600$ cells compared to 53,900 noradrenergic cells in the human locus coeruleus (Baker et al., 1989). The present study confirmed the paucity of tyrosine hydroxylase-immunoreactive soma in the subregions of the dorsal raphe. On the other hand, a moderately dense network of tyrosine hydroxylase-positive fibers was observed in these nuclei (Fig. 5). Because there is no evidence that serotonergic neurons express the NET gene, the dense binding of $\left[{ }^{3} \mathrm{H}\right]$ nisoxetine to NETs in the dorsal raphe suggests strongly that these NETs reside on tyrosine hydroxylase-positive noradrenergic terminals. The coexistence of NETs and tyrosine-hydroxylase immunostaining in the dorsal raphe nuclei also implies that at least part of the tyrosine hydroxylase immunostaining in the dorsal raphe nuclei is noradrenergic. Farley and Hornykiewicz (1977) have demonstrated a moderate concentration of norepinephrine in the human dorsal raphe nuclei, approximately one-third of the norepinephrine concentration measured in the locus coeruleus. The existence of norepinephrine and its transporter in the dorsal raphe demonstrates the influence of noradrenergic output on serotonergic neurons of the human dorsal raphe nuclei.

$\left[{ }^{3} \mathrm{H}\right]$ nisoxetine binding to NET in the dorsal raphe also appears to have a distribution similar to the distribution of PH8 immunostaining of serotonergic neurons, implying that NETexpressing noradrenergic fibers terminate near or on serotonergic cell bodies in the human dorsal raphe. In rats, direct innervation of serotonergic neurons by noradrenergic terminals has been demonstrated using electron microscopy (Baraban and Aghajanian, 1981). In fact, the rat dorsal raphe receives one of the richest noradrenergic innervations in the brain (Saavedra et al., 1976; Levitt and Moore, 1979; Baraban and Aghajanian, 1981). Interruption of noradrenergic transmission by systemic administration of an $\alpha$-adrenoceptor antagonist or iontophoretic application of $\alpha$-adrenoceptor antagonist in the vicinity of serotonergic neurons completely suppresses their spontaneous firing (Baraban and Aghajanian, 1980). Iontophoretic application of norepinephrine during the suppression of serotonergic cell activity produced by phentolamine or WB4104 , antagonists of $\alpha$-adrenoceptors, can rapidly restore firing of these neurons to their normal activity (Baraban and Aghajanian, 1980). Consistent with the dense noradrenergic innervation in the dorsal raphe, a relatively high concentration of $\left[{ }^{3} \mathrm{H}\right]$ nisoxetine-binding sites was found within this nucleus in rats (Tejani-Butt, 1992), as well as a high density of $\alpha_{1}$ - and $\alpha_{2}$-adrenoceptors (Jones et al., 1985; Nicholas et al., 1993; Pieribone et al., 1994; Scheinin et al., 1994). Thus, anatomical and physiological data demonstrate direct, functional innerva- 
tion of serotonergic neurons in the dorsal raphe nuclei by noradrenergic neurons.

The uptake of norepinephrine from the synapse is the principal mechanism by which the action of norepinephrine is terminated in the synapse and, the NET is the critical protein that mediates this process. As such, the NET is an important site of action of antidepressant drugs as well as drugs of abuse. The expression of NETs appears to be regulated by antidepressant treatments (Bauer and Tejani-Butt, 1992; Szot et al., 1993; Shores et al., 1994) and by other drugs that manipulate the synaptic availability of norepinephrine, e.g., reserpine and monoamine oxidase inhibitors (Lee et al., 1983). Given the critical role of NETs in noradrenergic transmission, it seems possible that alterations in the expression of NETs could contribute to the etiology of psychiatric illnesses such as depression or drug abuse/withdrawal disorders. The quantitative map of the binding of $\left[{ }^{3} \mathrm{H}\right]$ nisoxetine to NETs in the human locus coeruleus and dorsal raphe nuclei presented here provides the groundwork for such investigations.

\section{REFERENCES}

Backstrom IT, Ross SB, Marcusson JO (1989) [ $\left.{ }^{3} \mathrm{H}\right]$ Desipramine binding to rat brain tissue: binding to both noradrenergic uptake sites and sites not related to noradrenaline neurons. J Neurochem 52:1099-1106.

Backstrom IT, Marcusson JO (1990) High- and low-affinity $\left[{ }^{3} \mathrm{H}\right]$ desipramine-binding sites in human postmortem brain tissue. Neuropsychobiology 23:68-73.

Baker KG, Tork I, Hornung JP, Halasz P (1989) The human locus coeruleus complex: an immunohistochemical and three dimensional reconstruction study. Exp Brain Res 77:257-270.

Baker KG, Halliday GM, Tork I (1990) Cytoarchitecture of the human dorsal raphe nucleus. J Comp Neurol 301:147-161.

Baker KG, Halliday GM, Hornung J-P, Geffen LB, Cotton RGH, Tork I (1991) Distribution, morphology and number of monoaminesynthesizing and substance P-containing neurons in the human dorsal raphe nucleus. Neuroscience 42:757-775.

Baraban JM, Aghajanian GK (1980) Suppression of serotonergic neuronal firing by $\alpha$-adrenoceptor antagonists: evidence against GABA mediation. Eur J Pharmacol 66:287-294.

Baraban JM, Aghajanian GK (1981) Noradrenergic innervation of serotonergic neurons in the dorsal raphe: demonstration by electron microscopic autoradiography. Brain Res 204:1-11.

Barker EL, Blakely RD (1995) Norepinephrine and serotonin transporters. Molecular targets of antidepressant drugs. In: Psychopharmacology. A fourth generation of progress (Bloom FE, Kupfer DJ, eds), pp 321-333. New York: Raven.

Bartholini G, Richards JG, Pletscher A (1970) Dissociation between biochemical and ultra-structural effects of 6-hydroxydopamine in rat brain. Experientia (Basel) 26:142-144.

Bauer ME, Tejani-Butt SM (1992) Effects of repeated administration of desipramine or electroconvulsive shock on norepinephrine uptake sites measured by $\left[{ }^{3} \mathrm{H}\right]$ nisoxetine autoradiography. Brain Res 582:208-214.

Blakely RD, De Felice LJ, Hartzell HC (1994) Molecular physiology of norepinephrine and serotonin transporters. J Exp Biol 196:263-281.

Blanchard V, Raisman-Vozari R, Savasta M, Hirsch E, Javoy-Agid F, Feuerstein C, Agid Y (1993) Cellular quantification of tyrosine hydroxylase in the rat brain by immunoautoradiography. J Neurochem 61:617-626.

Bloom FE, Algeri S, Gropetti A, Revuelta A, Costa E (1969) Lesions of central norepinephrine terminals with 6-OH-dopamine: biochemistry and fine structure. Science 166:1284-1286.

Bogerts B (1981) A brainstem atlas of catecholaminergic neurons in man, using melanin as a natural marker. J Comp Neurol 197:63-80.

Chan-Palay V, Asan E (1989) Quantitation of catecholamine neurons in the locus coeruleus in human brains of normal young and older adults and in depression. J Comp Neurol 287:357-372.

Cheetham SC, Viggers JA, Butler SA, Prow MR, Heal DJ (1996) $\left[{ }^{3} \mathrm{H}\right]$ nisoxetine: a radioligand for noradrenaline reuptake sites: correlation with inhibition of $\left[{ }^{3} \mathrm{H}\right]$ noradrenaline uptake and effect of DSP-4 lesioning and antidepressant treatments. Neuropharmacology 18:63-70.

Coggeshall RE, Lekan HA (1996) Methods for determining numbers of cells and synapses: a case for more uniform standards of review. J Comp Neurol 364:6-15.

Cortes R, Soriano E, Pazos A, Probst A, Palacios JM (1988) Autoradiography of antidepressant binding sites in the human brain: localization using $\left[{ }^{3} \mathrm{H}\right]$ imipramine and $\left[{ }^{3} \mathrm{H}\right]$ paroxetine. Neuroscience 27:473-496.

Cotton RGH, McAdam W, Jennings I, Morgan FJ (1988) A monoclonal antibody to aromatic amino acid hydroxylases: identification of the epitope. Biochem J 255:193-196.

Donnan GA, Kaczmarczyk SJ, Paxinos G, Chilko PJ, Kalnins RM, Woodhouse DG, Mendelsohn FAO (1991) Distribution of catecholamine uptake sites in human brain as determined by quantitative $\left[{ }^{3} \mathrm{H}\right]$ mazindol autoradiography. J Comp Neurol 304:419-434.

Farley IJ, Hornykiewicz O (1977) Noradrenaline distribution in subcortical areas of the human brain. Brain Res 126:53-62.

Foote SL, Bloom FE, Aston-Jones G (1983) Nucleus locus coeruleus: new evidence of anatomical and physiological specificity [review]. Physiol Rev 63:844-914.

Fritschy JM, Grzanna R (1989) Immunohistochemical analysis of the neurotoxic effects of DSP-4 identifies two populations of noradrenergic axon terminals. Neuroscience 30:181-197.

Fuxe K, Hokfelt T, Agnati LF, Johansson M, Goldstein M, Perez de la Mora M, Passanti L, Tapia R, Teran L, Palacio J (1978) Mapping out central catecholamine neurons: immunohistochemical studies on catecholamine-synthesizing enzymes. In: Psychopharmacology: a generation of progress (Lipton MA, DiMascio A, Killam K, eds), pp 67-95. New York: Raven.

Gross-Isseroff R, Israeli M, Biegon A (1988) Autoradiographic analysis of $\left[{ }^{3} \mathrm{H}\right]$ desmethylimipramine binding in the human brain postmortem. Brain Res 456:120-126.

Gurevich EV, Joyce JN (1996) Comparison of $\left[{ }^{3} \mathrm{H}\right]$ paroxetine and $\left[{ }^{3} \mathrm{H}\right]$ cyanoimipramine for quantitative measurement of serotonin transporter sites in human brain. Neuropsychopharmacology 14:309-323.

Herbert H, Saper CB (1992) Organization of medullary adrenergic and noradrenergic projections to the periaqueductal gray matter in the rat. J Comp Neurol 315:34-52.

Hoffman BJ (1994) Expression cloning of a serotonin transporter: a new way to study antidepressant drugs. Pharmacopsychiatry 27:16-22.

Hoffman BJ, Mezey E, Brownstein MJ (1991) Cloning of a serotonin transporter affected by antidepressants. Science 254:579-580.

Hrdina PD, Foy B, Hepner A, Summers RJ (1990) Antidepressant binding sites in the brain: autoradiographic comparison of $\left[{ }^{3} \mathrm{H}\right]$ paroxetine and $\left[{ }^{3} \mathrm{H}\right]$ imipramine localization and relationship to serotonin transporter. J Pharmacol Exp Ther 252:410-418.

Iversen LL, Rossor MN, Reynolds GP, Hills R, Roth M, Mountjoy CQ, Foote SL, Morrison JH, Bloom FE (1983) Loss of pigmented dopamine- $\alpha$-hydroxylase positive cells from locus coeruleus in senile dementia of the Alzheimer type. Neurosci Lett 39:95-100.

Jones LS, Gauger LL, Davis JN (1985) Anatomy of brain alpha 1 -adrenergic receptors: in vitro autoradiography with [ $\left.{ }^{125} \mathrm{I}\right]$-HEAT. J Comp Neurol 231:190-208.

Klimek V, Ordway GA (1996) Disrtibution of $\alpha_{2}$-adrenoceptors in human locus coeruleus. Brain Res 741:263-274.

Laduron PM, Robbyns M, Schotte A (1982) $\left[{ }^{3} \mathrm{H}\right]$ desipramine and $\left[{ }^{3} \mathrm{H}\right] \mathrm{i}-$ mipramine binding are not associated with noradrenaline and serotonin uptake in the brain. Eur J Pharmacol 78:491-493.

Lee C-M, Javitch JA, Snyder SH (1983) Recognition sites for norepinephrine uptake: regulation by neurotransmitter. Science 220:626-629.

Levitt P, Moore RY (1979) Origin and organization of brain stem catecholamine innervation in the rat. J Comp Neurol 186:505-528.

Lorang D, Amara S, Simerly RB (1994) Cell-type-specific expression of catecholamine transporters in the rat brain. J Neurosci 14:4903-4914.

Mann DMA, Yates PO (1979) The effects of ageing on the pigmented cells of the human locus coeruleus and substantia nigra. Acta Neuropathol 47:93-98.

Nicholas AP, Pieribone V, Hokfelt T (1993) Distributions of mRNAs for alpha-2 adrenergic receptor subtypes in rat brain: an in situ hybridization study. J Comp Neurol 328:575-594.

Olszewski J, Baxter D (1954) Cytoarchitecture of the human brain stem. Philadelphia: Lippincott.

Ordway GA (1995) Effect of noradrenergic lesions on subtypes of $\alpha_{2}$ adrenoceptors in rat brain. J Neurochem 64:1118-1126.

Pacholczyk T, Blakely RD, Amara SG (1991) Expression cloning of a cocaine and antidepressant-sensitive human noradrenaline transporter. Nature 350:350-354.

Pieribone VA, Nicholas AP, Dagerlind A, Hokfelt T (1994) Distribution 
of $\alpha_{1}$ adrenoceptors in rat brain revealed by in situ hybridization experiments utilizing subtype-specific probes. J Neurosci 14:4252-4268.

Saavedra JM, Grobecker H, Zivin J (1976) Catecholamines in the raphe nuclei of the rat. Brain Res 114:339-345.

Scheinin M, Lomasney JW, Hayden-Hixson DM, Schambra UB, Caron MG, Lefkowitz RJ, Fremeau Jr RT (1994) Distribution of $\alpha_{2}$ adrenergic receptor subtype gene expression in rat brain. Mol Brain Res 21:133-149.

Shores MM, Szot P, Veith RC (1994) Desipramine-induced increase in norepinephrine transporter mRNA is not mediated via $\alpha_{2}$ receptors. Mol Brain Res 27:337-341.

Stockmeier CA, Shapiro LA, Haycock JW, Thompson PA, Lowy MT (1996) Quantitative subregional distribution of serotonin sA $_{1 \mathrm{~A}}$ receptors and serotonin transporters in the human dorsal raphe. Brain Res 727:1-12.

Szot P, Ashliegh EA, Kohen R, Petrie E, Dorsa DM, Veith R (1993) Norepinephrine transporter mRNA is elevated in the locus coeruleus following short- and long-term desipramine treatment. Brain Res 618:308-312.
Tejani-Butt SM (1992) $\left[{ }^{3} \mathrm{H}\right]$ Nisoxetine: a radioligand for quantitation of norepinephrine uptake sites by autoradiography or by homogenate binding. J Pharmacol Exp Ther 260:427-436.

Tejani-Butt SM, Brunswick DJ, Frazer A (1990) $\left[{ }^{3} \mathrm{H}\right]$ nisoxetine: a new radioligand for norepinephrine uptake sites in brain. Eur J Pharmacol 191:239-243.

Tejani-Butt SM, Ordway GA (1992) Effect of age on $\left[{ }^{3} \mathrm{H}\right]$ nisoxetine binding to uptake sites for norepinephrine in the locus coeruleus of humans. Brain Res 583:312-315.

Tejani-Butt SM, Yang J, Zaffar H (1993) Norepinephrine transporter sites are decreased in the locus coeruleus in Alzheimer's disease. Brain Res 631:147-150.

Tork I, Hornung J-P (1990) Raphe nuclei and the serotonergic system. In: The human nervous system (Paxinos G, ed). San Diego: Academic.

Van Bockstaele EJ, Aston-Jones G (1992) Collateralized projections from neurons in the rostral medulla to the nucleus locus coeruleus, the nucleus of the solitary tract and the periaqueductal gray. Neuroscience 49:653-668. 